\title{
An investigation on the tribological behaviors of steel/copper and steel/steel friction pairs via lubrication with a graphene additive
}

\author{
Junyuan MAO ${ }^{1}$, Guangyan CHEN ${ }^{1}$, Jun ZHAO ${ }^{2, *}$, Yongyong HE $^{1, *}$, Jianbin LUO ${ }^{1}$ \\ ${ }^{1}$ State Key Laboratory of Tribology, Tsinghua University, Beijing 100084, China \\ ${ }^{2}$ College of Mechanical and Electrical Engineering, Beijing University of Chemical Technology, Beijing 100029, China \\ Received: 05 May 2019 / Revised: 22 July 2019 / Accepted: 09 September 2019 \\ (C) The author(s) 2019.
}

\begin{abstract}
In this study, the tribological behaviors of graphene as a lubricant additive for steel/copper and steel/steel friction pairs were compared. For the steel/copper friction pair, the graphene sheets remarkably decreased the coefficient of friction and wear scar depth under low loads, but these slightly increased under high loads. The steel/steel friction pair showed excellent tribological properties even under high loads. Severe plastic deformation on the copper surface reduced the stability of the graphene tribofilm because of a rough copper transfer film on the steel during the running-in period. The results provide a better understanding of the mechanism of graphene as a lubricant additive.
\end{abstract}

Keywords: steel/copper and steel/steel friction pairs; tribological behaviors; graphene additives; transfer film

\section{Introduction}

Steel and copper alloys are common materials and constituents of engineering machinery. Steel/steel and steel/copper friction pairs are typical moving parts in machines such as bearings and hydraulic pumps. Several studies have been conducted on friction and wear in steel/copper [1-6] and steel/steel [7, 8] friction pairs under lubricated or dry friction conditions. In general, steel has relatively low wear during friction owing to its high hardness according to the Archard wear equation [9]. In contrast, the wear is relatively high for copper because of severe plastic deformation $[10,11]$, which leads to the formation of delamination cracks on the surface of the copper [12]. Nonetheless, plastic deformation of copper alloy under repeated friction could contribute to the excellent frictional conformability of its surface [13]. The transfer film of copper [14] or copper compound [15] can decrease the wear of friction pairs during the friction process.
Low energy consumption and long service lifetimes are important in engineering machinery. Steel/copper and steel/steel friction pairs lubricated by oil or oil with traditional lubrication additives do not fulfill these requirements. Graphene is a 2D laminated material that has been explored extensively as a novel lubricant additive to further improve the properties of lubrication oil [16-24]. It has excellent mechanical and thermal properties as well as good physical and chemical stability [25]. Although some studies on graphene lubricant additives have been conducted on steel/ copper [18, 20] or steel/steel [16, 17, 25] friction pairs, only a few have compared the tribological behaviors of these two friction pairs as well as the differences between the lubrication mechanisms of steel/copper and steel/ steel friction pairs under graphene lubrication.

Here, the tribological behavior of graphene as a lubricant additive for steel/copper and steel/steel friction pairs is comparatively studied for the first time. The two kinds of friction pairs lubricated by graphene

* Corresponding authors: Yongyong HE, E-mail: heyy@mail.tsinghua.edu.cn; Jun ZHAO, E-mail: zhaojun@mail.buct.edu.cn 
were tested on a ball-on-disk tribometer with reciprocating sliding conditions. High-resolution transmission electron microscopy (HRTEM), Raman spectrum, and X-ray diffraction (XRD) were used to observe the micromorphology and microstructure of thermallyreduced graphene oxide (TRGO). Scanning electron microscopy (SEM) was used to observe the micromorphology of the wear scar. Graphene as a lubricant additive has better lubrication properties for steel/steel friction pairs relative to steel/copper friction pairs. The results offer important guidance on suitable friction pairs lubricated with graphene-based lubricants.

\section{Material and methods}

\subsection{Material processing and sample preparation}

The graphene (TRGO) used here was synthesized via the thermal reduction of commercially available graphene oxide (The Sixth Element Materials Technology Co., Ltd., Changzhou, China). The graphene oxide was thermally reduced at $700{ }^{\circ} \mathrm{C}$ for $4 \mathrm{~h}$ in $\mathrm{Ar}$ atmosphere via $\mathrm{KOH}$, and subsequently treated with ball-milling, which was discussed in our previous work [25]. The base oil used in the experiments was hydraulic oil (Kunlun Lubricant, China) with a kinematic viscosity of $13.2 \mathrm{~mm}^{2} / \mathrm{s}$ at $40{ }^{\circ} \mathrm{C}$ and $4.9 \mathrm{~mm}^{2} / \mathrm{s}$ at $100{ }^{\circ} \mathrm{C}$. The samples were commercially available bearings made of steel GCr15 (AISI 52100) and brass H62. The composition and mechanical parameters of the friction pairs are listed in Table 1.

\subsection{Experimental procedure}

Tribological tests were performed on a UMT-3 (CETR, USA) tribometer in a ball-on-disk reciprocating friction and wear mode (Fig. 1) with a sliding distance of $3 \mathrm{~mm}$, frequency of $0.5 \mathrm{~Hz}$, and test duration of $30 \mathrm{~min}$ at room temperature. The applied load ranged from 1 to $15 \mathrm{~N}$ with maximum Hertzian pressures of $0.7-$ 1.6 GPa for the steel/copper friction pair, and 0.9-
2.2 GPa for the steel/steel friction pair. The upper ball sample (GCr15, Ø4 mm) and lower disk sample (GCr15 or H62, Ø24 $\mathrm{mm} \times 8 \mathrm{~mm}$ ) were cleaned ultrasonically by petroleum ether before testing. The TRGO sheets with concentrations ranging from 0.1 to $1 \mathrm{wt} \%$ were added to the base oil, fully mixed by magnetic stirring for $60 \mathrm{~min}$, and then fully dispersed with ultrasonic treatment for $40 \mathrm{~min}$ at $40^{\circ} \mathrm{C}$.

The micromorphology and microstructure of the TRGO sheets were analyzed with HRTEM (JEM-2010, Japan) with an accelerating voltage of $120 \mathrm{kV}$. XRD with the Bruker D8 Advance diffractometer (Bruker, USA) was performed over the $2 \theta$ range of $10^{\circ}-90^{\circ}$, which identified the crystallinity, crystallographic orientation, and interlayer distance of the graphene sheets. The Raman spectra of the TRGO sheets were measured with a Jobin Yvon HR800 confocal Raman system with $632.8 \mathrm{~nm}$ diode laser excitation at $-70{ }^{\circ} \mathrm{C}$ to identify the defects of TRGO sheets and study the graphene-based tribofilm. A 3D white light interfering profilometer (Zygo Nexview, USA) was used to measure the wear loss and outline of the wear scar after the tests.

\section{Results and discussion}

\subsection{Characteristics of the graphene additive}

Figure 2(a) shows that the 2D sizes of TRGO sheets are $100-600 \mathrm{~nm}$. These are small enough to easily enter the contact area of the rubbing surfaces of friction pairs to influence the friction reduction and anti-wear properties $[17,26]$. TEM was done to observe the microstructure of TRGO sheets (Fig. 2(b)). Figure 2(b) presents the high magnification TEM image of a TRGO sheet, and the stacked atomic layers show an ordered laminated microstructure [27]. However, there are also some short atomic layers indicating that some defects exist in the sheet. The XRD of TRGO sheets shown in Fig. 2(c) have strong (002) diffraction peak at $2 \theta=24.8^{\circ}$,

Table 1 The composition and mechanical parameters of the friction pairs.

\begin{tabular}{|c|c|c|c|c|c|c|}
\hline $\begin{array}{l}\text { Friction } \\
\text { pair }\end{array}$ & Composition & $\begin{array}{l}\text { Hardness } \\
\text { /HV }\end{array}$ & $\begin{array}{l}\text { Young's modulus } \\
/ \mathrm{GPa}\left(20^{\circ} \mathrm{C}\right)\end{array}$ & $\begin{array}{l}\text { Poisson's ratio } \\
\qquad\left(20^{\circ} \mathrm{C}\right)\end{array}$ & $\begin{array}{l}\text { Tensile strength } \\
\qquad / \mathrm{MPa}\end{array}$ & $\underset{/ \mathrm{nm}}{\text { Roughness }}$ \\
\hline H62 & $\mathrm{Cu}(62 \%)+\mathrm{Zn}(38 \%)$ & $90-140$ & 100 & 0.36 & 410 & $6-9$ \\
\hline GCr15 & $\begin{array}{c}\mathrm{Fe}(97 \%)+\mathrm{C}(1 \%)+\mathrm{Cr}(1.5 \%)+ \\
\text { Trace amount of Mn, Si, S, P, and Mo }\end{array}$ & $740-750$ & 210 & 0.3 & 861.3 & $\begin{array}{c}5-8 \text { (disc) } \\
10-15 \text { (ball) }\end{array}$ \\
\hline
\end{tabular}




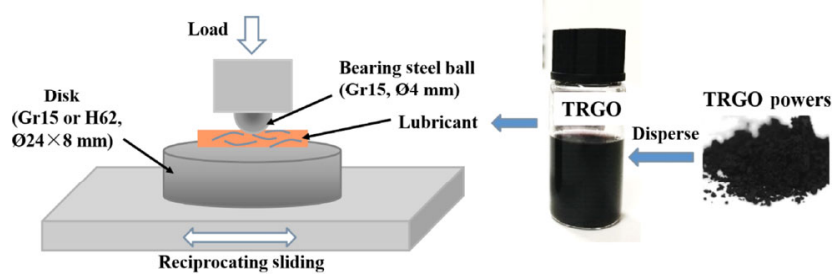

Fig. 1 Configuration of a ball-on-disk experimental setup for reciprocating sliding conditions.
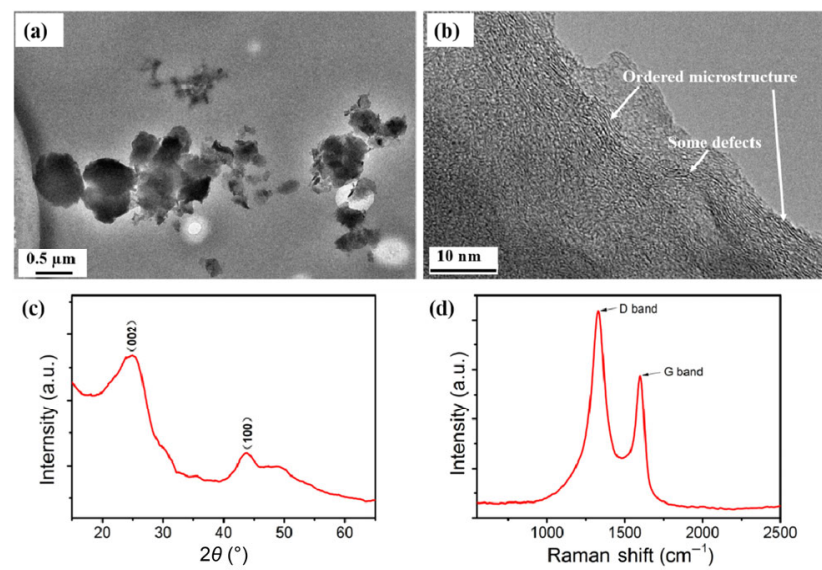

Fig. 2 Micromorphology and microstructure characteristics of TRGO. (a)-(b) TEM image (TRGO sheets were dispersed on a copper mesh support film), (c) XRD diffraction, and (d) Raman spectra.

which implies an interlayer distance of $3.6 \AA$, approximating the theoretical value $(\sim 3.4 \AA)$ [28]. The weak diffraction peaks at $2 \theta$ intervals of $40^{\circ}-50^{\circ}$ are due to (100) and (101) reflections [29]. The average height of TRGO sheets can be calculated from the (002) full width at half maximum values $\left(4.2^{\circ}\right)[29,30]$. Thus, the average height of TRGO sheets is $19.4 \AA$ according to Scherrer's equation $[18,31]$, which indicates nearly six graphene layers of TRGO.

The Raman spectrum of TRGO in Fig. 2(d) has two intense peaks in the $\mathrm{D}$ band and $\mathrm{G}$ band at $1,330 \mathrm{~cm}^{-1}$ and $1,599 \mathrm{~cm}^{-1}$, respectively. The $\mathrm{D}$ band means that there are some $\mathrm{sp}^{3}$ carbons in the graphene lattices, i.e., some defects exist in TRGO sheets. The G band is attributed to the in-plane vibration of $\mathrm{sp}^{2}$ atoms and the doubly degenerate zone center $\mathrm{E}_{2 \mathrm{~g}}$ mode $[32,33]$. The intensity ratio of the $\mathrm{D}$ band and $\mathrm{G}$ band $\left(I_{\mathrm{D}} / I_{\mathrm{G}}\right.$, 1.46) also suggests some defects on the surfaces and edges of TRGO sheets [34, 35], which is consistent with the result of TEM analysis. In the subsequent thermal reduction process, oxygen atoms escaped in the form of carbon dioxide, which took away some of the carbon atoms, thereby resulting in defects. However, the graphene in this study showed a higher degree of exfoliation because of activation by $\mathrm{KOH}$ at high temperature. Our previous works showed that the above graphene has good tribological properties because of its high degree of exfoliation despite some structural defects [23, 25]. The highly exfoliated graphene shows much lower Van der Waals' force between layers because of larger interlayer spacing, which not only improves flexibility and self-adaptation at the friction interface but also promotes lubrication by decreasing the energy barrier of the interlayer.

\subsection{Friction and wear}

Figure 3(a) shows that the mean coefficients of friction (COFs) during sliding for $30 \mathrm{~min}$ of the base oil (within the range $0.20-0.23$ ) slightly decreased with load from 1 to $15 \mathrm{~N}$ for the steel/copper friction pair; this is much higher than that with TRGO lubricant (0.08-0.10). However, a large increase in the mean COFs of TRGO lubricant occurred when the load increased to more than $3 \mathrm{~N}$. For the steel/steel friction pair, the mean COFs of both the base oil and TRGO lubricant during sliding for $30 \mathrm{~min}$ were $0.132-0.140$ and $0.092-0.100$, respectively. These values are nearly independent of the load.

The trends in COFs of the TRGO lubricant over the sliding time of the steel/copper friction pair are seen in Fig. 3(b). The COFs were steady throughout the friction process under loads of 1 and $3 \mathrm{~N}$, but increased under loads of $4.5-15 \mathrm{~N}$, indicating an unsteady lubrication condition when the load is more than $3 \mathrm{~N}$. The wear scar depth of copper disks lubricated by the base oil and TRGO lubricant in Fig. 3(d) roughly increased with load, and shows that the wear scar depth of copper disks lubricated by TRGO lubricant is much lower than that lubricated by the base oil at loads of 1 and $3 \mathrm{~N}$. With loads of 4.5-15 N, the wear scar depth of copper disks lubricated by TRGO lubricant increased to almost the same value as that lubricated by base oil, or even higher. Under steady lubrication condition of $3 \mathrm{~N}$, the mean $\mathrm{COF}$ and wear scar depth of TRGO lubricant was 0.081 and $0.68 \mu \mathrm{m}$, which is $25.2 \%$ and $64.2 \%$ that of base oil ( 0.23 and $1.06 \mu \mathrm{m})$, respectively.

The COFs of TRGO lubricant are shown as a 
function of sliding time for steel/steel friction pairs in Fig. 3(c). The COFs of the TRGO lubricant were steady throughout the friction process without any obvious change over friction time. The wear scar depth of the steel disks lubricated by TRGO lubricant and base oil in Fig. 3(e) also roughly increased with load. The sample with TRGO lubricant was much lower than that with base oil, especially when the loads were 1-4.5 N. Almost no wear was measured by the 3D white light interfering profilometer. At a load of $3 \mathrm{~N}$, the mean COF and wear scar depth of TRGO lubricant was 0.092 and $0.008 \mu \mathrm{m}$, which is $67.6 \%$ and $3.1 \%$ of that with base oil $(0.136$ and $0.257 \mu \mathrm{m})$, respectively.

The analyses in Fig. 3 shows that the COFs of TRGO lubricant can be steady, and the wear scar depths were much lighter than those with base oil at all test loads for the steel/steel friction pair. This indicates that the graphene sheets were firmly absorbed on the rubbing interface of the steel/steel friction pair to form a tribofilm, and completely separated the asperities
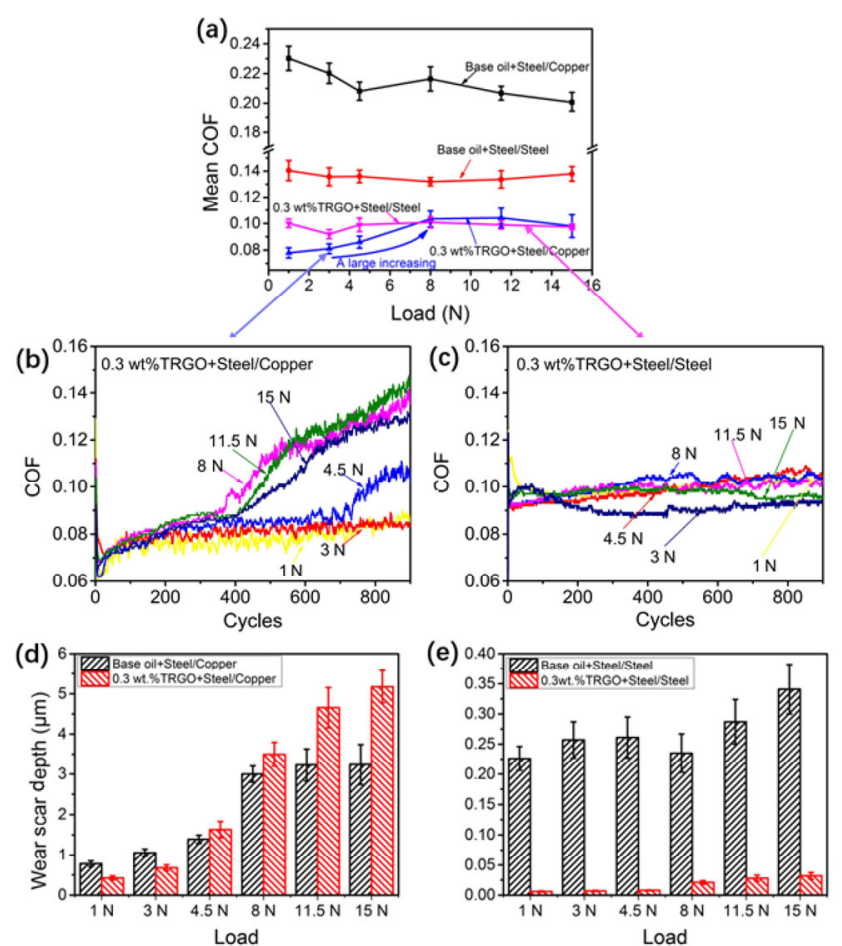

Fig. 3 Coefficients of friction (COFs) and wear scar depths of $0.3 \mathrm{wt} \%$ TRGO lubricant and the base oil for (b) and (d) the steel/copper and (c) and (d) steel/steel friction pairs: (a) the mean COFs of $0.3 \mathrm{wt} \%$ TRGO lubricant and the base oil as functions of load; (b) and (c) the trends in COFs of $0.3 \mathrm{wt} \%$ TRGO lubricant over sliding time; (d) and (e) the wear scar depths of TRGO lubricant and the base oil. on the interface. The steel/copper friction pair had good lubrication properties with TRGO lubricant only at low loads $(\leq 3 \mathrm{~N})$. However, the COFs and wear scar depths of TRGO lubricant were gradually close to the level of base oil, and became even larger at high loads (more than $3 \mathrm{~N}$ ). This indicates that the graphene sheets were no longer firmly absorbed at the rubbing interface of the steel/copper friction pair, and the resulting tribofilm was easily destroyed under high loads. Figure 4 shows that $0.3 \mathrm{wt} \%$ is the optimal concentration for TRGO lubricant to realize the lowest COF and slightest wear. At lower concentrations, TRGO was unable to form a stable transferrable protective film on the friction interface, which resulted in metalto-metal contact of the friction pairs. As concentration increased, TRGO could aggregate in lubricants and the accompanying clusters may be too large to enter the friction interfaces. In our previous works, the optical concentration of nano-additives was approximately $0.5 \mathrm{wt} \%$ [21]. This study confirmed that $0.3 \mathrm{wt} \%$ is the optimal concentration for TRGO lubricant for steel/copper friction pairs to realize the lowest COF and slightest wear.

Figures 5(a) and 5(b) show that both COFs of the base oil and TRGO lubricant first increased and then decreased to a steady-state value during the first 10-40 s of rubbing tests under a low or high load. The running-in process at the beginning of sliding with base oil [36] led to increasing COFs with direct contact of the partial asperities of the rubbing interfaces. With base oil containing TRGO sheets, a graphene boundary tribofilm was formed along with the running-in process at the beginning of sliding. The graphene sheets were uniformly dispersed in the base oil and could be physically absorbed at the rubbing interface to quickly form a graphene boundary tribofilm
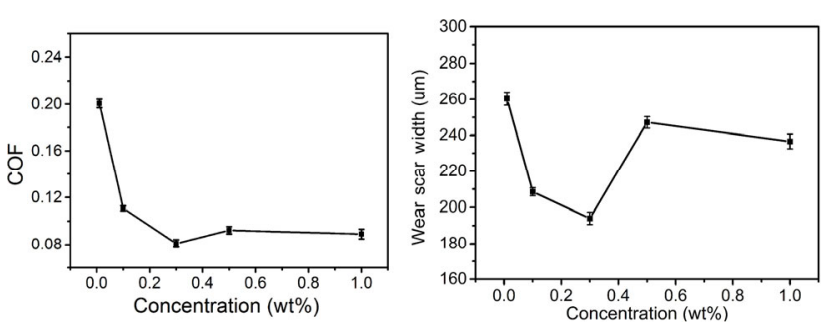

Fig. 4 Variations of COFs and wear scar width with increasing concentrations for TRGO lubricant for the steel/copper friction pair. 
(a)

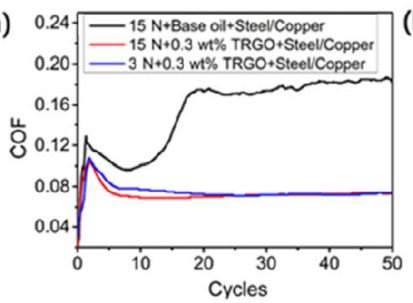

(b)

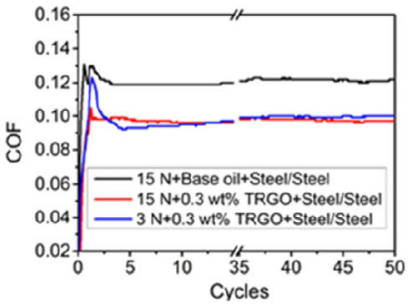

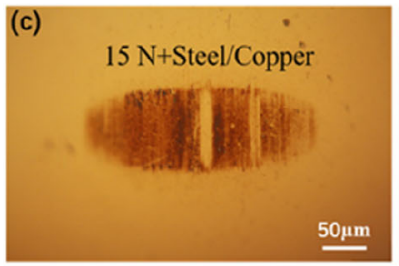

(d)

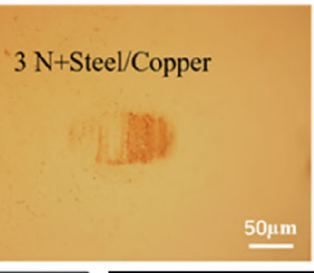

(e)
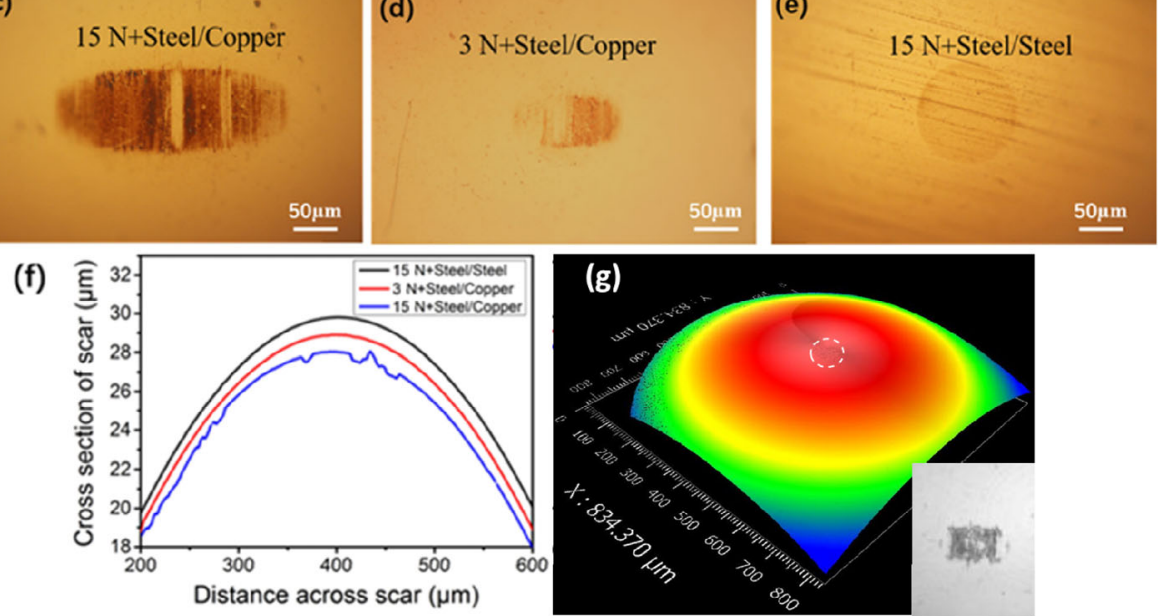

Fig. 5 COFs and wear scar of steel/copper and steel/steel friction pairs. (a) and (b) The COFs of TRGO in the first 100 seconds of rubbing tests; (c)-(e) the wear scars of the upper samples of steel balls after 25 seconds of rubbing tests under $15 \mathrm{~N}$ or $3 \mathrm{~N}$ measured by an optical microscope; (f) the cross section of wear scars in (c)-(e) in the horizontal direction; (g) the 3D image of the steel ball against copper disk lubricated by TRGO under $15 \mathrm{~N}$ for $30 \mathrm{~min}$. The inset is the corresponding optical microscope image of the ball surface.

throughout the contact area of the sliding distance. This is attributed to the pressure and shear action at the beginning of sliding.

The running-in and graphene boundary tribofilmforming process may lead to fast wear because of the sub-optimal lubrication films at the rubbing interface; this is especially true at the interface of the steel/copper friction pair. Therefore, the first $25 \mathrm{~s}$ of rubbing tests were further studied. The wear scars on the upper ball samples (steel balls) after $25 \mathrm{~s}$ of rubbing are shown in Figs. 5(c)-5(e). There are obvious elliptical and rough wear scars on the surface of the steel ball against the copper disk with a high load (15 N). A smooth wear scar exists at low loads ( $\mathrm{N}$ ). However, only a slight circular imprint is seen on the surface of the steel ball against the steel disk; almost no wear is seen on the cross-section line of the scar in Fig. 5(f). The steel/ copper friction pair had extremely severe plastic deformation on the surface of the copper disk at high load after sliding for a short time. Some of the copper on the disk transferred to the surface of the steel ball, i.e., there was a rough copper transfer film that affected the formation of the graphene boundary tribofilm on the rubbing interface. As shown in Fig. 5(f), the ball with copper transfer film has quite a rough profile. We can directly observe the copper transfer film in Fig. $5(\mathrm{~g})$, and this film is obviously rougher than the areas outside it on the ball.

Next, we investigated the effect of the rough copper transfer film on graphene boundary tribofilm. Firstly, to obtain a rough copper transfer film, steel ball sliding against a copper disc was carried out, lubricated by TRGO under $15 \mathrm{~N}$ for $25 \mathrm{~s}$ and marked as ball A. Secondly, two parallel tests (test A and test B) with steel balls and steel disks initially lubricated by TRGO were conducted under $15 \mathrm{~N}$ for $10 \mathrm{~min}$. Thirdly, the ball in test A was replaced by ball A (with a rough copper transfer film) and the friction test continued without changing rubbing position, as shown in line 2 of Fig. 6 . In contrast, the other ball in test B was replaced by a new ball (without a rough copper transfer film), shown in line 3 of Fig. 6.

Line 2 of Fig. 6 shows that the COF was steady at approximately 0.105 during the first 10 min of friction, 


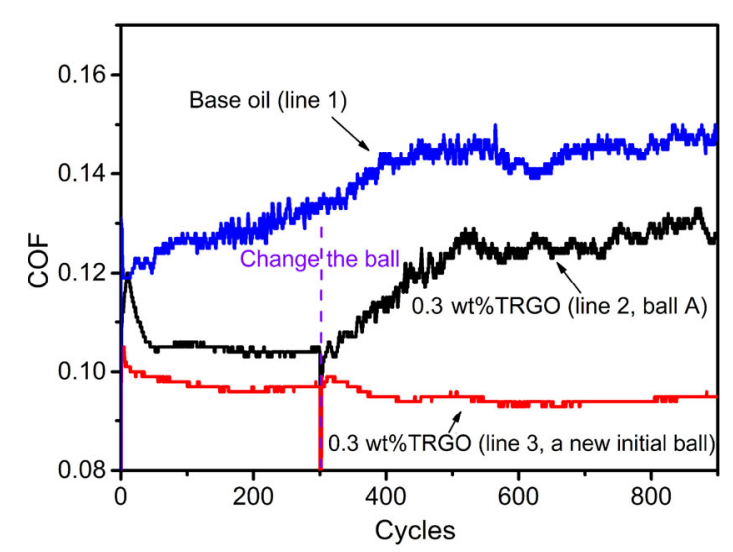

Fig. $6 \mathrm{COFs}$ of steel/steel friction pairs at $15 \mathrm{~N}$.

but rapidly increased to 0.13 within the next $8 \mathrm{~min}$. It then gradually increased close to that of the base oil (shown in line 1 of Fig. 6). This means that the rough copper transfer film stuck to the steel ball and increased the ball's roughness, leading to the deterioration of lubrication [37] by destroying the excellent graphene boundary tribofilm. In other words, low and steady COF no longer existed. Line 3 of Fig. 6 shows that the COF was steady throughout the friction test and was not affected when the ball was replaced by a new one without a rough copper transfer film. This confirms that the rough copper transfer film is the decisive factor in the destruction of graphene boundary tribofilm.

\subsection{Morphological analysis of worn surfaces}

Figure 7 shows copper accumulation on the two sides

(a)

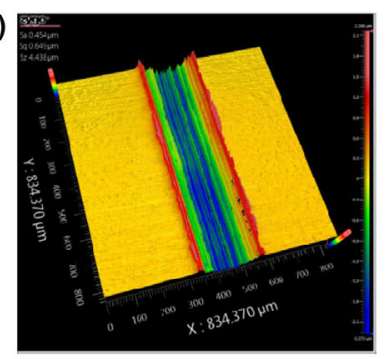

(e) 1.

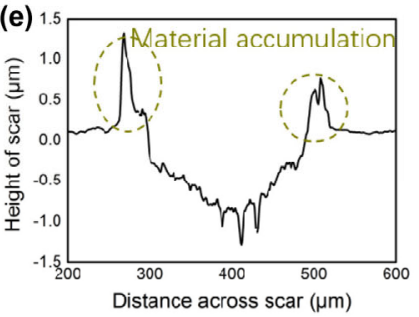

(b)
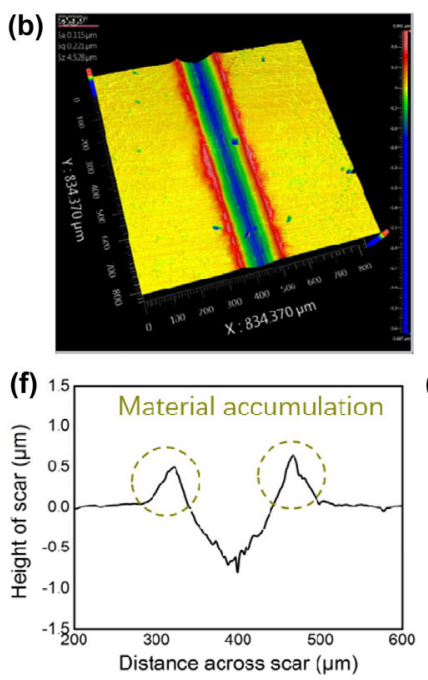

of the wear scar of the copper disk lubricated by base oil or TRGO (Figs. 7(a), 7(b), 7(e), and 7(f)). There was slight adhesive wear in the wear scar of the steel disk lubricated by base oil (Figs. 7(c) and 7(g)) but essentially no wear in the sample lubricated by TRGO (Figs. 7(d) and $7(\mathrm{~h})$ ). Because of the low Young's modulus of copper (1.1 times smaller than that of steel (Table 1)), severe plastic deformation occurred on the copper disk [10-12]. Under pressure and shear action, some of the copper in the contact area was pushed toward the two sides of the wear scar, causing a severe plough effect owing to severe plastic deformation.

Figure 8 shows the severe plough effect and adhesive wear on the wear scar of steel balls and copper disks under dry friction (Figs. 8(a) and 8(d)), and with base oil (Figs. 8(b) and 8(e)). The sample was smooth with relatively slight wear for the TRGO lubricant (Figs. 8(c) and $8(\mathrm{f})$ ). Table 2 presents the $\mathrm{Cu}$ and $\mathrm{Zn}$ elements and the composition of the copper materials (H62). These were measured on the surface of steel balls, and the data confirmed that some of the copper materials transferred from the copper disks to their paired steel balls, i.e., the rough copper transfer film [20]. Figure 9 shows the severe abrasive wear on the surface of steel disks under dry friction (Figs. 9(a) and 9(d)). There was a plough effect and adhesive wear for the base oil (Figs. 9(b) and 9(e)), and almost no wear for the TRGO lubricant (Figs. 9(c) and 9(f)). In Table 2, the content of $C$ at the wear scar lubricated by TRGO was much

(c)

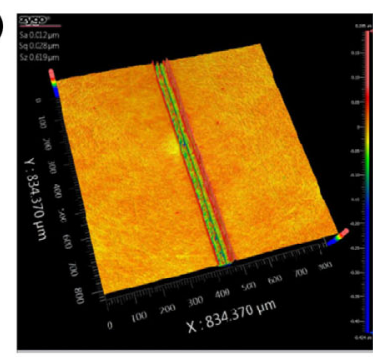

(g)

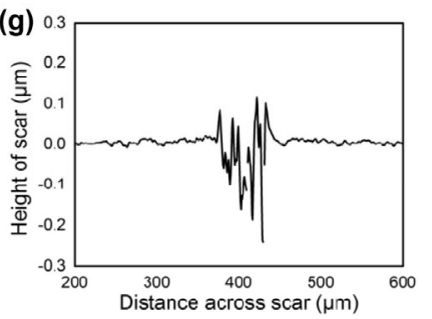

(d)

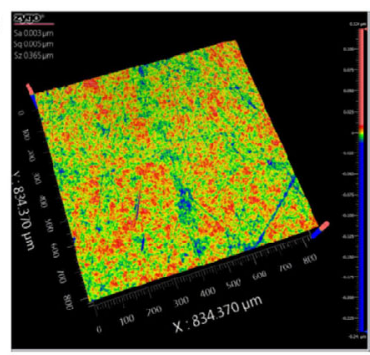

(h)

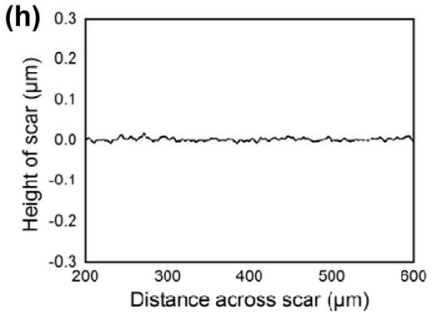

Fig. 7 (a)-(d) Three-dimensional white light interference images of the wear scars and (e)-(f) height of wear scars after friction tests at 3 N. Here, panels (a) and (e) are the copper disk lubricated with the base oil. Panels (b) and (f) are copper disks lubricated by TRGO lubricant, panels (c) and (g) are the steel disk lubricated by the base oil, and (d) and (h) for steel disks lubricated with TRGO lubricant. 

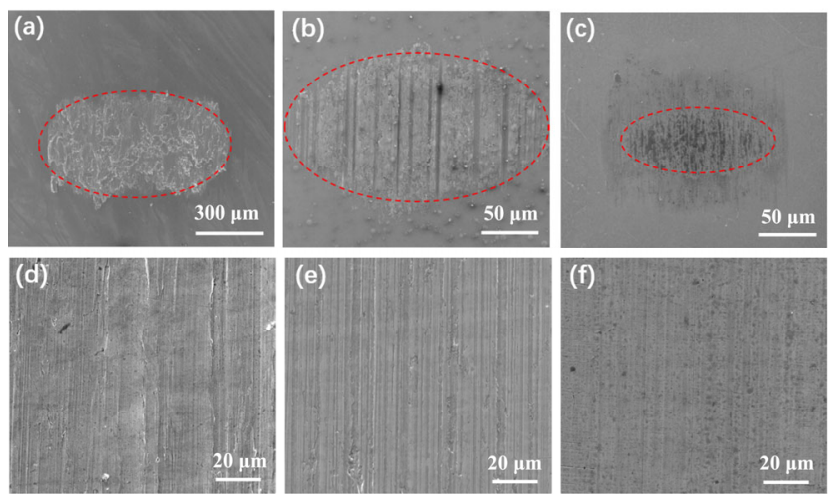

Fig. 8 SEM images of wear scars for (a)-(c) steel ball against (d)-(f) copper disk after friction tests in 3 N. Panels (a) and (d) are dry friction, (b) and (e) are the base oil, and (c) and (f) are with TRGO lubricant.

Table 2 EDX analysis of wear scar on the surface of the steel ball after friction.

\begin{tabular}{ccccccc}
\hline \multirow{2}{*}{ Lubricant } & \multicolumn{6}{c}{ Chemical elements } \\
\cline { 2 - 7 } & $\mathrm{Cu}$ & $\mathrm{Zn}$ & $\mathrm{Fe}$ & $\mathrm{Cr}$ & $\mathrm{O}$ & $\mathrm{C}$ \\
\hline Dry & 53.9 & 36.6 & 7.7 & 0.2 & 0.3 & 1.3 \\
Base oil & 61.0 & 17.5 & 18.7 & 0.4 & 1.9 & 0.5 \\
TRGO lubricant & 4.3 & 3.4 & 83.8 & 1.4 & 4.4 & 2.7 \\
\hline
\end{tabular}
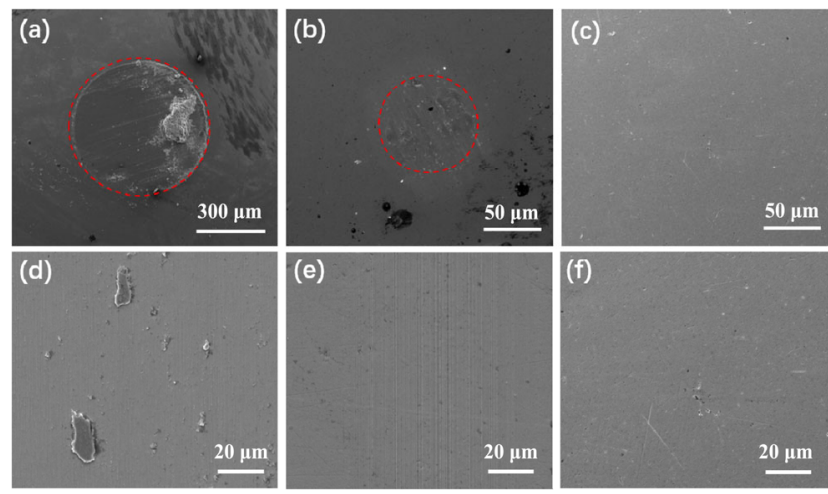

Fig. 9 SEM images of wear scars for (a)-(c) steel balls against (d)-(f) steel disks after friction tests in 3 N. Panels (a) and (d) for dry friction, (b) and (e) are with the base oil, and (c) and (f) are with the TRGO lubricant.

higher than that of dry friction and base oil. This implies that TRGO was absorbed on the surface. The Raman spectra of wear scars on the balls against steel and copper with TRGO lubricant are shown in Fig. 10. There are D and G bands in both spectra, which are the characteristic bands of graphene. This confirms that regardless of the friction pairs, the TRGO sheets can be firmly absorbed on the surface. In addition, the $I_{\mathrm{D}} / I_{\mathrm{G}}$ on the wear scars was reduced to approximately
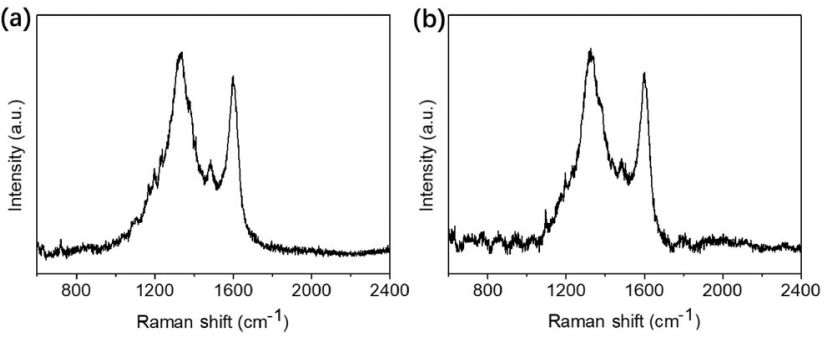

Fig. 10 Raman spectra of the wear scars of the balls sliding against steel disk (a) and copper disk (b) with the TRGO lubricant after friction tests in $3 \mathrm{~N}$ from Figs. 8 and 9.

1.2, while the initial $I_{\mathrm{D}} / I_{\mathrm{G}}$ of TRGO sheets was 1.46 (Fig. 2(d)). This means that the structure of the TRGO sheets that formed on the wear scars turned into ordering, which is proved to be beneficial for lubrication [23].

All the wear scars on the surface of steel balls rubbed with copper disks were elliptical, while those rubbed with steel disks were circular (Figs. 8(a)-8(c) with Figs. 9(a)-9(c)). The larger eccentricity of an ellipse indicates that it is flatter. The eccentricities of the elliptical wear scars on the surface of steel balls lubricated by the base oil and TRGO were 0.824 and 0.924, respectively, indicating a flatter elliptical wear scar on the sample lubricated with TRGO.

\subsection{The influence of severe plastic deformation}

The evolution of the graphene boundary tribofilm during sliding is shown in Fig. 11. Many graphene

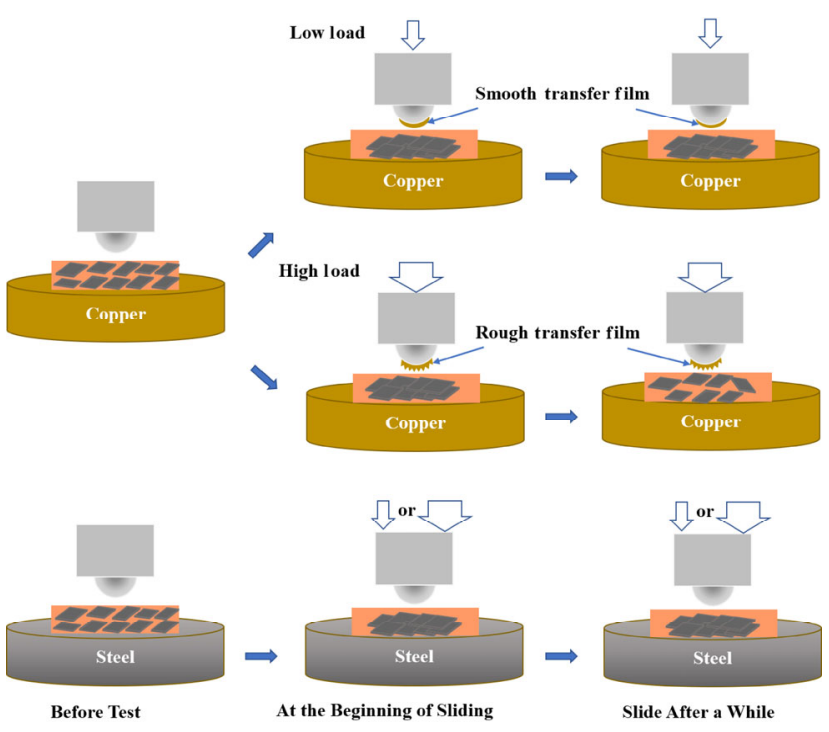

Fig. 11 The evolution of the graphene boundary tribofilm during sliding. 
sheets dispersed in the base oil were absorbed at the interface of rubbing surfaces via pressure and shear action. These sheets formed a low shearing graphene boundary tribofilm throughout the contact area of the sliding distance.

Under high load, the copper disk with severe plastic deformation led to a rough copper transfer film on the steel ball at the beginning of sliding. There are many sharp asperities on the rough copper transfer film. When the sharp asperities are in contact with the graphene boundary tribofilm, the contact stress at the contact point is quite high, causing the wear of the graphene boundary tribofilm. Thus, TRGO fails to form a complete tribofilm to separate the two contact surfaces, resulting in high wear of the steel/copper pair, which eventually leads to the failure of lubrication. Under low load, relatively small copper transfers formed the relatively smooth copper transfer film with asperities. The graphene boundary tribofilm is strong enough to withstand the asperities. The copper transfer film may even become smoother during friction with the stable graphene boundary tribofilm at the interface of rubbing surfaces owing to the excellent frictional conformability of copper [13], which contributes to good lubrication.

According to the Hertz contact theory [38], a circular point contact area forms when a smooth ball makes contact with a smooth disk. Thus, the reason for the elliptical wear scar on the steel balls rubbed with copper disks is somewhat unclear. Figure 12 shows that severe plastic deformation leads to severe material accumulation. This is analogous to two "hills" that are higher than the upper surface of the copper disk. These areas are at the two sides of the wear scar of the copper disk under pressure and shear action, and lead to the copper being transferred to the steel ball's surface. Copper materials in both the wear area and the "hills" below and above the upper surface of copper disks transferred to steel ball's surface and simultaneously formed wear scars on it with reciprocating sliding action. The "hills" then widened the wear scar on the steel ball's surface perpendicular to the sliding direction after being rubbed with steel balls. This explains why elliptical wear scars formed on the surface of steel balls. The smaller wear scar of
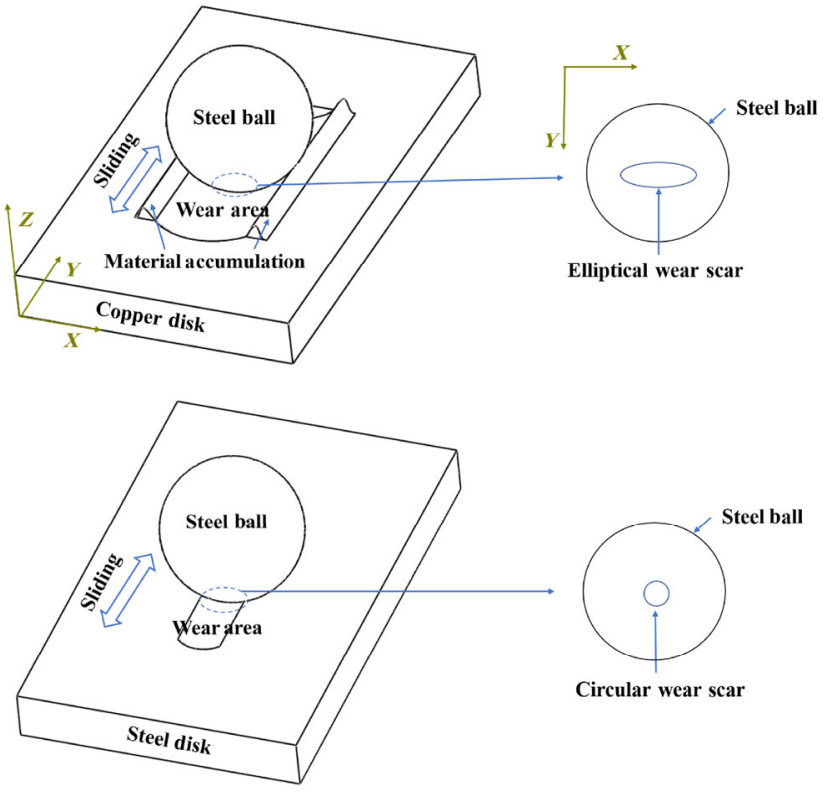

Fig. 12 Wear scars of the steel balls, copper disk and steel disk after sliding.

copper disks lubricated by TRGO lubricant led to larger eccentricity of the elliptical wear scar, i.e., flatter elliptical wear scar versus that lubricated by base oil.

\section{Conclusions}

The tribological behaviors of steel/copper and steel/ steel friction pairs were compared under the lubrication of a graphene lubricant. The steel/copper friction pair with TRGO sheets had a COF and wear scar depth that decreased under low load, but slightly increased under high load. The steel/steel friction pair showed excellent tribological properties even under high load with TRGO sheet lubrication. The low-shearing tribofilm of graphene contributed to low COF and wear scar depth under low loads. However, for the steel/ copper friction pair, severe plastic deformation on the friction surface of copper greatly reduced the stability of the tribofilm at the friction interface under high loads because a rough transfer film of copper formed on the steel friction surface during the running-in period. Furthermore, severe plastic deformation resulted in the accumulation of copper on the two sides of the wear scar of the copper disk along the sliding direction. The accumulation process widened the wear scar widths of the steel balls during sliding, which generated elliptical wear scars on the balls, 
while the wear scars were circular for the steel/steel friction pair. Unlike the steel/copper friction pair, abrasive wear and adhesive wear were dominant for the steel/steel friction pair. This indicates more significant lubrication properties than the steel/copper friction pair under the lubrication of graphene additive. This study provides important guidance on choosing suitable friction pairs lubricated by graphene-based lubricants.

\section{Acknowledgements}

This work was supported by National Natural Science Foundation of China (Nos. 51527901 and 51335005), the National Key Basic Research Program of China (973 Program, No. 2014CB046404) and Tribology Science Fund of State Key Laboratory of Tribology (No. SKLTKF18A02).

Open Access: This article is licensed under a Creative Commons Attribution 4.0 International License, which permits use, sharing, adaptation, distribution and reproduction in any medium or format, as long as you give appropriate credit to the original author(s) and the source, provide a link to the Creative Commons licence, and indicate if changes were made.

The images or other third party material in this article are included in the article's Creative Commons licence, unless indicated otherwise in a credit line to the material. If material is not included in the article's Creative Commons licence and your intended use is not permitted by statutory regulation or exceeds the permitted use, you will need to obtain permission directly from the copyright holder.

To view a copy of this licence, visit http://creativecommons.org/licenses/by/4.0/.

\section{References}

[1] Bouchoucha A, Chekroud S, Paulmier D. Influence of the electrical sliding speed on friction and wear processes in an electrical contact copper-stainless steel. Appl Surf Sci 223(4): 330-342 (2004)

[2] Chen B M, Bi Q L, Yang J, Xia Y Q, Hao J C. Tribological properties of solid lubricants (graphite, h-BN) for $\mathrm{Cu}$-based P/M friction composites. Tribol Int 41(12): 1145-1152
(2008)

[3] Marui E, Endo H. Effect of reciprocating and unidirectional sliding motion on the friction and wear of copper on steel. Wear 249(7): 582-591 (2001)

[4] Moshkovich A, Perfilyev V, Lapsker I, Rapoport L. Stribeck curve under friction of copper samples in the steady friction state. Tribol Lett 37(3): 645-653 (2009)

[5] Moshkovich A, Perfilyev V, Meshi L, Samuha S, Cohen S, Cohen H, Laikhtman A, Rapoport L. Friction, wear and structure of $\mathrm{Cu}$ samples in the lubricated steady friction state. Tribol Int 46(1): 154-160 (2012)

[6] Perfilyev V, Moshkovich A, Lapsker I, Rapoport L. Friction and wear of copper samples in the steady friction state. Tribol Int 43(8): 1449-1456 (2010)

[7] Wang Y R, Yu Q L, Ma Z F, Huang G W, Cai M R, Zhou F, Liu W M. Significant enhancement of anti-friction capability of cationic surfactant by phosphonate functionality as additive in water. Tribol Int 112: 86-93 (2017)

[8] Wu H, Zhao J W, Cheng X W, Xia W Z, He A S, Yun J H, Huang S Q, Wang L Z, Huang H, Jiao S H, et al. Friction and wear characteristics of $\mathrm{TiO}_{2}$ nano-additive water-based lubricant on ferritic stainless steel. Tribol Int 117: 24-38 (2018)

[9] Archard J F. Contact and rubbing of flat surfaces. J Appl Phys 24(8): 981-988 (1953)

[10] Emge A, Karthikeyan S, Kim H J, Rigney D A. The effect of sliding velocity on the tribological behavior of copper. Wear 263(1-6): 614-618 (2007)

[11] Emge A, Karthikeyan S, Rigney D A. The effects of sliding velocity and sliding time on nanocrystalline tribolayer development and properties in copper. Wear 267(1-4): 562-567 (2009)

[12] Zhang Y S, Han Z, Wang K, Lu K. Friction and wear behaviors of nanocrystalline surface layer of pure copper. Wear 260(9-10): 942-948 (2006)

[13] Saffar A, Shojaei A. Effect of rubber component on the performance of brake friction materials. Wear 274-275: 286-297 (2012)

[14] Yu L G, Yang S R, Liu W M, Xue Q J, Bahadur S. Action of transfer film in improving friction and wear behaviors of iron- and copper-filled poly(ether ether ketone) composites. J Appl Polym Sci 76(2): 179-184 (2000)

[15] Bahadur S, Gong D L, Anderegg J. The role of copper compounds as fillers in transfer film formation and wear of nylon. Wear 154(2): 207-223 (1992)

[16] Chen Z, Liu Y H, Luo J B. Tribological properties of fewlayer graphene oxide sheets as oil-based lubricant additives. Chin J Mech Eng 29(2): 439-444 (2016)

[17] Eswaraiah V, Sankaranarayanan V, Ramaprabhu S. Graphene- 
based engine oil nanofluids for tribological applications. $A C S$ Appl Mater Interfaces 3(11): 4221-4227 (2011)

[18] Mao J Y, Zhao J, Wang W, He Y Y, Luo J B. Influence of the micromorphology of reduced graphene oxide sheets on lubrication properties as a lubrication additive. Tribol Int 119: 614-621 (2018)

[19] Uflyand I E, Zhinzhilo V A, Burlakova V E. Metal-containing nanomaterials as lubricant additives: State-of-the-art and future development. Friction 7(2): 93-116 (2019)

[20] Zhao J, He YY, Wang YF, Wang W, Yan L, Luo J B. An investigation on the tribological properties of multilayer graphene and $\mathrm{MoS}_{2}$ nanosheets as additives used in hydraulic applications. Tribol Int 97: 14-20 (2016)

[21] Zhao J, Li Y R, Mao J Y, He Y Y, Luo J B. Synthesis of thermally reduced graphite oxide in sulfuric acid and its application as an efficient lubrication additive. Tribol Int 116: 303-309 (2017)

[22] Zhao J, Li Y R, Wang Y F, Mao J Y, He Y Y, Luo J B. Mild thermal reduction of graphene oxide as a lubrication additive for friction and wear reduction. $R S C A d v$ 7(3): 1766-1770 (2017)

[23] Zhao J, Mao J Y, Li Y R, He Y Y, Luo J B. Friction-induced nano-structural evolution of graphene as a lubrication additive. Appl Surf Sci 434: 21-27 (2018)

[24] Zheng D, Cai Z B, Shen M X, Li Z Y, Zhu M H. Investigation of the tribology behaviour of the graphene nanosheets as oil additives on textured alloy cast iron surface. Appl Surf Sci 387: 66-75 (2016)

[25] Li Y R, Zhao J, Tang C, He Y Y, Wang Y F, Chen J, Mao J Y, Zhou Q Q, Wang B Y, Luo J B, et al. Highly exfoliated reduced graphite oxide powders as efficient lubricant oil additives. Adv Mater Interfaces 3(22): 1600700 (2016)

[26] Lin J S, Wang L W, Chen G H. Modification of graphene platelets and their tribological properties as a lubricant additive. Tribol Lett 41(1): 209-215 (2011)

[27] Wang G X, Yang J, Park J, Gou X L, Wang B, Liu H, Yao J. Facile synthesis and characterization of graphene nanosheets.

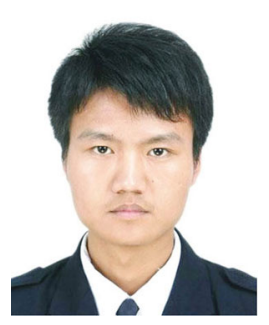

Junyuan MAO. He received his bachelor degree in engineering in 2015 from Wuhan University of Technology, China. Then, he was a
J Phys Chem C 112(22): 8192-8195 (2008)

[28] Stankovich S, Dikin D A, Piner R D, Kohlhaas K A, Kleinhammes A, Jia Y Y, Wu Y, Nguyen S T, Ruoff R S. Synthesis of graphene-based nanosheets via chemical reduction of exfoliated graphite oxide. Carbon 45(7): 1558-1565 (2007)

[29] Milev A, Wilson M, Kannangara G S K, Tran N. X-ray diffraction line profile analysis of nanocrystalline graphite. Mater Chem Phys 111(2-3): 346-350 (2008)

[30] Stobinski L, Lesiak B, Malolepszy A, Mazurkiewicz M, Mierzwa B, Zemek J, Jiricek P, Bieloshapka I. Graphene oxide and reduced graphene oxide studied by the XRD, TEM and electron spectroscopy methods. J Electr Spectrosc Relat Phenom 195: 145-154 (2014)

[31] Monshi A, Foroughi M R, Monshi M R. Modified scherrer equation to estimate more accurately nano-crystallite size using XRD. World J Nano Sci Eng 2(3): 154-160 (2012)

[32] Ferrari A C, Meyer JC, Scardaci V, Casiraghi C, Lazzeri M, Mauri F, Piscanec S, Jiang D, Novoselov K S, Roth S, et al. Raman spectrum of graphene and graphene layers. Phys Rev Lett 97(18): 187401 (2006)

[33] Kudin K N, Ozbas B, Schniepp H C, Prud'homme R K, Aksay I A, Car R. Raman spectra of graphite oxide and functionalized graphene sheets. Nano Lett 8(1): 36-41 (2008)

[34] Ammar M R, Galy N, Rouzaud J N, Toulhoat N, Vaudey C E, Simon P, Moncoffre N. Characterizing various types of defects in nuclear graphite using Raman scattering: Heat treatment, ion irradiation and polishing. Carbon 95: 364-373 (2015)

[35] Xiao J K, Zhang L, Zhou K C, Li J G, Xie X L, Li Z Y. Anisotropic friction behaviour of highly oriented pyrolytic graphite. Carbon 65: 53-62 (2013)

[36] Cavatorta M P, Cusano C. Running-in of aluminum/steel contacts under starved lubrication: Part I: Surface modifications. Wear 242(1-2): 123-132 (2000)

[37] Daikhin L, Urbakh M. Roughness effect on the frictional force in boundary lubrication. Phys Rev E 49(2): 1424-1429 (1994)

[38] Johnson K L. One hundred years of Hertz contact. Proc Inst Mech Eng 196(1): 363-378 (1982)

M.S. student in State Key Laboratory of Tribology, and received his M.S. degree in mechanical engineering in 2018 from Tsinghua University, China. His research interest includes graphene lubrication additives. 


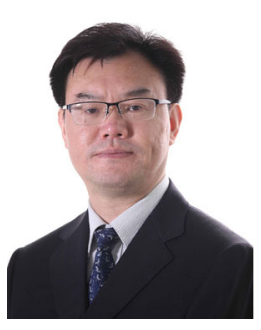

Yongyong HE. He received his M.S. and Ph.D. degrees in mechanical engineering from Southeast University, China, in 1994 and 1997, respectively. He joined Tsinghua

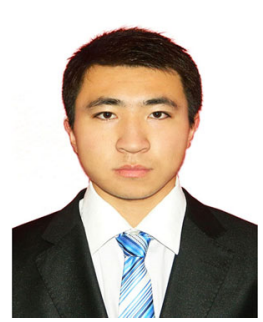

Jun ZHAO. He is an associate professor in College of Mechanical and Electrical Engineering, Beijing University of Chemical Technology, China. He received his Ph.D. degree
University from 1999. Now, he is a professor in the State Key Laboratory of Tribology. His research areas cover surface/interface modification, CMP and ultrasmooth surface polishing.

in mechanical engineering from Tsinghua University, China. His research interests are the synthesis of advanced lubricating nanomaterials and applications of antifriction and antiwear materials. 